\title{
A simple, inexpensive, robust and sensitive dot-blot assay for equal detection of the nonstructural-1 glycoprotein of all dengue virus serotypes
}

Andrew KI Falconar ${ }^{*}$ and Claudia ME Romero-Vivas

\begin{abstract}
Background: Detection of dengue virus (DENV) soluble/excreted (s/e) form of the nonstructural-1 (NS1) glycoprotein in patient acute-phase sera is ideal for diagnosis. The commercially-available detection assays are, however, too expensive for routine use and have low specificity, particularly for the s/e NS1 glycoprotein of DENV-2 and DENV-4, which are important causes of lethal human disease worldwide.

Methods: Mouse monoclonal antibodies (MAbs) were generated and screened against s/e NS1 glycoprotein purified from each DENV serotype to obtain those that reacted equally with each serotype, but not with yellow fever virus (YFV) s/e NS1 glycoprotein or human serum proteins. One MAb, MAb 2C4.6, was further tested against these DENV glycoproteins in human sera using simple, peroxidase-labelled secondary antibody/substrate-developed dot-blot assays.
\end{abstract}

Results: Optimal quenching of endogenous human serum peroxidases was attained using $3 \% \mathrm{H}_{2} \mathrm{O}_{2}$ in $\mathrm{H}_{2} \mathrm{O}$ for 5 min. MAb 2C4.6 showed an acceptable detection sensitivity of $\leq 32 \mathrm{ng} / \mathrm{ml}$ for the s/e NS1 glycoprotein of each DENV serotype but did not cross-react with the YFV s/e NS1 glycoprotein or human serum proteins. By contrast, the LX1 epitope-specific MAb, 3D1.4, showed similar detection sensitivity against only the DENV-1 NS1 glycoprotein, consistent with results from commercial DENV s/e NS1 glycoprotein detection assays.

DENV s/e NS1 glycoproteins were stable in human sera after drying on the nitrocellulose membranes and storage for one month at ambient temperature $\left(28^{\circ} \mathrm{C}\right)$ before being processed. The total assay time was reduced to $3 \mathrm{~h}$ without any loss of detection sensitivity. This dot-blot format was ideal for the circulating immune complex disruption step, which is required for increased DENV s/e NS1 glycoprotein detection.

Conclusions: This is the first study to determine the detection sensitivity of MAbs against known concentrations of s/e NS1 glycoprotein from each DENV serotype. The preparation of patient serum samples for dot-blot assays can be performed by staff with a basic level of training and storage at low temperatures (e.g., $-80^{\circ} \mathrm{C}$ ) is not necessary. These simple, inexpensive (US\$ 0.05/sample), robust, sensitive and relatively rapid assays, using improved MAbs such as MAb 2C4.6, should be ideal for the diagnosis of all DENV serotypes in DENV endemic regions.

Keywords: Dengue virus, Nonstructural-1 glycoprotein, Diagnostic, Monoclonal antibody, Dot-blot, Sensitivity, Low-cost

\footnotetext{
*Correspondence: afalconar@uninorte.edu.co

Laboratorio de Enfermedades Tropicales, Departmento de Medicina,

Universidad del Norte, Km 5 Antigua via Puerto Colombia, Barranquilla,

Colombia
} 


\section{Background}

Dengue viruses (DENVs) are the most important vectorborne human viruses in the world, causing an estimated 50-100 million infections in 100 countries and resulting in a self-limiting febrile illness called dengue fever (DF), which is sometimes associated with haemorrhage [1]. Approximately 500000 cases result in the more severe, life-threatening forms, due to plasma leakage, severe haemorrhage, shock and organ failure called either severe dengue disease (SDD) or dengue haemorrhagic fever/dengue shock syndrome (DHF/DSS). Up to 12500 people (2.5\% of all DF cases) die from SDD (DHF/DSS) annually [1]. Four DENV serotypes (DENV-1 to DENV4) have been identified, each of which may cause SDD (DHF/DSS).

During DENV infections, high concentrations of the native homo-hexameric form of the nonstructural-1 (NS1) glycoprotein are secreted from infected mammalian cells along with infectious DENV virions [2]. Purified secreted/ extracellular (s/e) DENV-2 NS1 glycoprotein added to normal human sera could be detected by an enzymelinked immunosorbent assay (ELISA) using a DENV NS1 glycoprotein complex-reactive monoclonal antibody, (MAb) 3D1.4 [3-5], with a sensitivity of $15 \mathrm{ng} / \mathrm{ml}$ [6]; although the DENV-2 NS1 glycoprotein-specific MAb, 1H7.4 [3], was slightly more sensitive $(4 \mathrm{ng} / \mathrm{ml})$ [6]. However, the ELISA using MAb 1H7.4 failed to detect the s/e NS1 glycoprotein in acute-phase sera from patients with primary DENV-2 infections collected in Thailand [6]. This assay also only detected the s/e NS1 glycoprotein in less than 50\% (DF: $40 \%$ and DHF/DSS: $45 \%$ ) of acute-phase sera from patients with secondary DENV-2 infections, at concentrations from $70 \mathrm{ng} / \mathrm{ml}$ up to $15,000 \mathrm{ng} / \mathrm{ml}$ [6]. Since these serum samples had undergone several freezethaw cycles, the results demonstrated the lability of the DENV s/e NS1 glycoprotein, probably through disruption of the relevant LD2 epitope (amino acid 25-33), [4] or loss of the LD2 epitope through cleavage of the NS1 glycoprotein at the conserved (amino acid 100-GKRS-103) dibasic amino-terminal protease cleavage site [7]. However, a capture ELISA using mouse and rabbit polyclonal antibodies (PAbs) detected the s/e NS1 glycoprotein in a moderate proportion of acute-phase sera from patients with either primary (77\% (10/13): 40 to $2,000 \mathrm{ng} / \mathrm{ml})$ or secondary (88\% (14/16): 10 to $2,000 \mathrm{ng} / \mathrm{ml})$ DENV-1 infections in French Guiana [8], identifying the s/e NS1 glycoprotein as a suitable target for DENV diagnostics.

MAbs used in DENV NS1 glycoprotein detection assays should react equally with the NS1 glycoproteins of each DENV serotype. However, MAb 3D1.4 and other MAbs (MAbs 1A12.3, 4H3.4 and 3A5.4) that bound the DENV complex LX1 epitope (amino acid 112-KYSWKTWGKA121) on the DENV NS1 glycoproteins reacted unequally with synthetic peptides containing the corresponding LX1 epitope of each DENV serotype, as follows: DENV-1 > DENV-3 > DENV-2 = DENV-4 [4].

Subsequently available commercial DENV s/e NS1 glycoprotein detection ELISAs used MAb 3D1.4 or other likely LX1 epitope-specific MAbs (Pan-E, PanBio/Inverness, Brisbane, Queensland, Australia; Platelia, Bio-Rad Laboratories, Marnes La Coquette, France, or Standard Diagnostics Inc., Kyonggi-do, South Korea). These assays are too expensive (\$US 5 to 10/sample) for routine screening of DENV-infected patients in poor, endemic areas, and have low sensitivity for the s/e NS1 glycoprotein of one or more DENV serotypes [9-11]. The Pan-E, Platelia and Standard Diagnostics DENV s/e NS1 glycoprotein detection ELISAs show low to moderate overall sensitivities with acute phase DENV serum samples (Standard Diagnostics: 55\%; Platelia: 56.5\% [11]; Pan-E: 56.3\%; Platelia: 68.0\% [10]; Pan-E: 64.9\%; Platelia: 83.2\% [9]). These assays also showed the highest sensitivity for DENV-1 (Standard Diagnostics: 70\%; Platelia: 70\% [11]; Pan-E: 79\%; Platelia: 87\% [10]; Pan-E 78.6\%; Platelia: 93\% [9]) and the lowest sensitivity for either DENV-2 (Standard Diagnostics: 41\%; Platelia: 38\% [11]; Pan-E: 62\%; Platelia: 63\% [10]; Pan-E: 76\%; Platelia 82\% [9]), or DENV-4 (Standard Diagnostics: 40\%; Platelia 73\% [11]; Pan-E: 52\%; Platelia: 79\% [10]; PanE: 36\%; Platelia: 71\% [9]). These results accounted for a large multi-country evaluation giving the lowest sensitivities of Pan-E and Platelia s/e NS1 detection ELISAs with acute-phase sera from Nicaraguan patients (Pan-E: 30\%; Platelia: 37\%), due to nearly all being infected with DENV2 (94\%), and not with DENV-1 (6\%) or DENV-3 (0\%) [10]. Thus, in summary, the strength of these assay reactions varied with DENV serotype, in the following order: DENV-1 $>$ DENV-3 $>$ DENV-2 $\geq$ DENV-4, similar to the anti-LX1 epitope MAbs [4].

More recent commercial DENV NS1 glycoprotein detection assays had even lower sensitivities. This was demonstrated in two well-conducted studies of NS1 antigen strip assays, Pan-E (average sensitivity: 45\% (range 30-59\%), PanBio (average sensitivity: 58.6\%: range 48.2-68.4\%), and Bio-Rad (average sensitivity: 58.6\%: range $48.2-$ 68.4\%) and the Standard Diagnostics lateral flow s/e NS1 detection assay (mean sensitivity: 48.5\%: range $38.5-58.7 \%)[11,12]$.

Commercially-available DENV NS1 glycoprotein detection/semi-quantification assays are too expensive for routine use in nearly all DENV endemic regions of the world, and all show significant differences in ability to detect the s/e NS1 glycoprotein of each DENV serotype [9-11,13-16]. Therefore there is an urgent need to develop improved MAbs for use in inexpensive DENV s/e NS1 glycoprotein detection assays.

We previously showed that the s/e NS1 glycoprotein from all four DENV serotypes could be detected in Indonesian patient sera using a simple dot-blot format, 
particularly when acid treatment and neutralisation steps were used [17]. However, these assays used an electrochemiluminescence (ECL) substrate coupled with photographic film, which is too expensive for routine use in DENV endemic areas. One advantage was that the glycoproteins were stable for month-long periods when dot-blotted, blocked, and dried onto nitrocellulose membranes before being developed [Falconar, unpublished]. It is also likely that improved immunoperoxidase detection sensitivity could be obtained in Western blot or dot-blot assays by incorporating $\mathrm{Ni}^{2+}$ ions into the 3,3'diaminobenzidine substrate, as demonstrated in immunohistochemical studies [18].

In the present study, we aimed to determine: a) whether we could generate mouse MAbs that could more equally detect the s/e NS1 glycoprotein of each serotype without cross-reacting with yellow fever virus (YFV) s/e NS1 glycoprotein or human serum proteins; b) the optimal parameters for quenching endogenous human serum peroxidases in simple dot-blot assays using one of these MAbs and standard 4-chloro-1-naphthol and 3,3'-diaminobenzidine tetrahydrochloride (CND) substrate precipitation; c) the detection sensitivities of such a MAb against the purified s/e NS1 glycoprotein of each DENV NS1 glycoprotein in these dot-blot assays; d) whether such a MAb would show superior detection of the s/e NS1 glycoprotein of each DENV serotype compared with MAb 3D1.4, which bound the LX1 epitope; e) whether the detection sensitivity could be increased by incorporating $1 \mathrm{mM} \mathrm{Ni}^{2+}$ ions into the CND substrate step; f) whether the DENV s/e NS1 glycoproteins in human sera were stable when blotted onto the membranes, blocked, dried and stored at either ambient temperature $\left(28^{\circ} \mathrm{C}\right.$ ) or at $4^{\circ} \mathrm{C},-20^{\circ} \mathrm{C}$ or $-80^{\circ} \mathrm{C}$ before being processed; g) whether these assays could be performed within a moderate time period (e.g. 3 hours); and h) the approximate cost of these assays (US\$/sample).

\section{Results}

Purification of s/e NS1 glycoproteins of each DENV serotype and YFV

Large (250-500 $\mu \mathrm{g})$ quantities of the soluble/extracellular (s/e) NS1 glycoproteins were obtained from DENV-1 (S\#14 strain), DENV-2 (S\#42 strain), DENV-3 (S\#25strain) and DENV-4 (S\#10 strain) serotypes isolated in our study site $[19,20]$ and from yellow fever virus (YFV) (17D-204 strain) by immunoaffinity purification from large infected Vero cell cultures as described previously [7,21]. These purified s/e NS1 glycoproteins were used for all mouse immunisations and immunoassays.

\section{Monoclonal antibodies (MAbs)}

In this study, only low numbers of the MAb-producing hybridomas (1.7\%: 16/960) showed strong cross-reactions with the s/e NS1 glycoprotein of multiple different DENV serotypes. MAb 2C4.6 was identified as a suitable candidate for further studies by its reactions in the preparative Western blot strip assays (Figure 1). In this study, supernatant from two 48-well plates containing MAb 2C4.6 (1 ml volume diluted $1: 2$ in $\mathrm{PBS} / \mathrm{T} / \mathrm{M}$ ) reacted strongly with the bands containing $35 \mathrm{ng}$ of the purified s/e NS1 glycoprotein of each DENV serotype but reacted very weakly with the DENV-2 NS1 glycoprotein when it was reduced with 2-mercaptoethanol. It did not cross-react with either the s/e NS1 glycoprotein of YFV, human serum proteins, or other cellular or DENV-2 proteins in a DENV-2-infected Vero cell lysate. The DENV s/e NS1 glycoproteins were almost exclusively converted into their monomeric forms after heat treatment. Therefore, MAb 2C4.6, which is of the immunoglobulin G (IgG) $2 \mathrm{~b}$ subclass, specifically bound to a conformationallydependent (2-mercaptoethanol reduction-sensitive) epitope on the s/e NS1 glycoprotein of each DENV serotype.

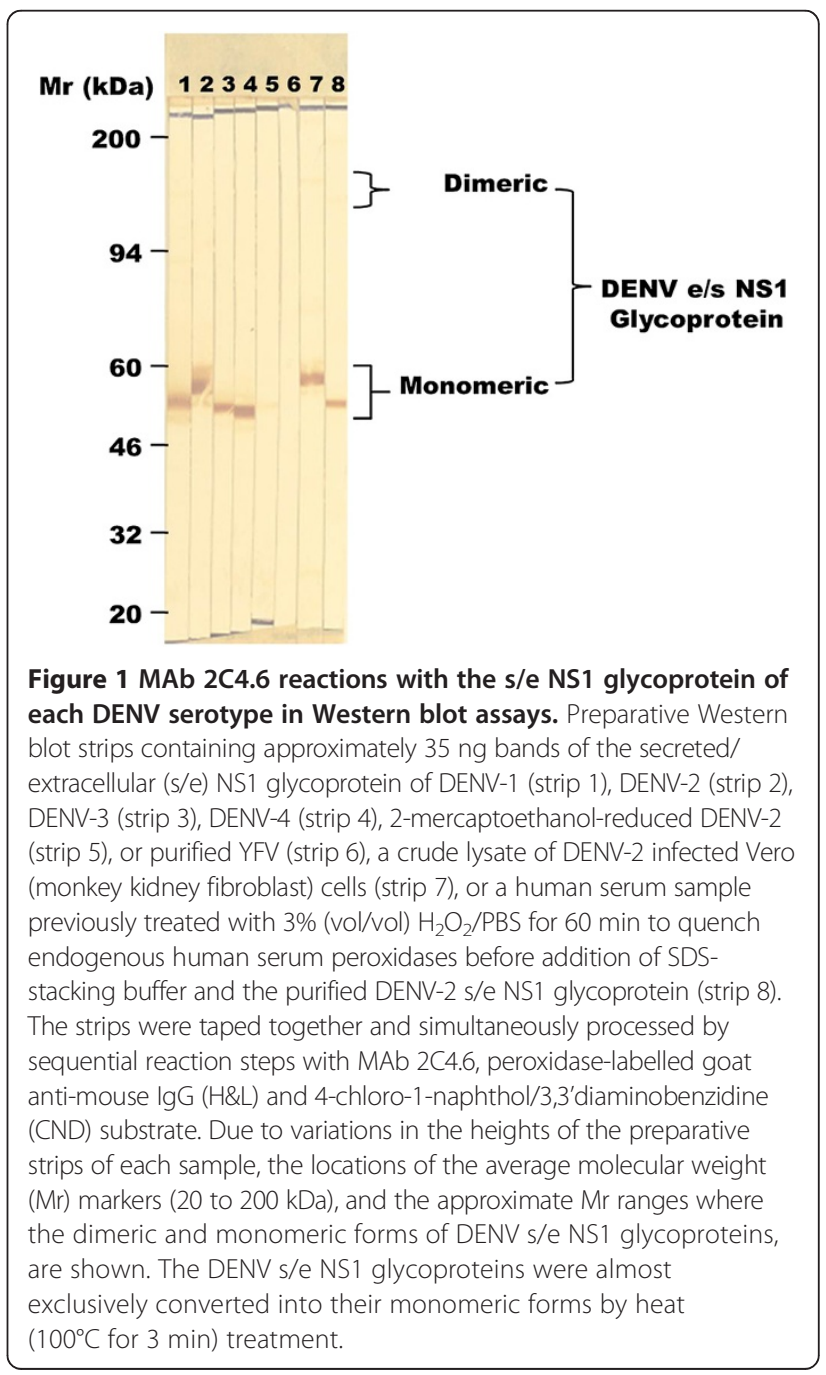


Optimal endogenous human serum peroxidase quenching for DENV-2 s/e NS1 glycoprotein detection by MAb 2C4.6 in dot-blot assays

The ability of $3 \% \mathrm{H}_{2} \mathrm{O}_{2}$ in either PBS, $40 \% \mathrm{MeOH} / \mathrm{PBS}$ or $\mathrm{H}_{2} \mathrm{O}$ to reduce the background noise in the dot-blot assays was assessed using three-fold serial dilutions of DENV-2 s/e NS1 glycoprotein prepared in neat human sera (Figure 2). The blots treated with $3 \% \mathrm{H}_{2} \mathrm{O}_{2}$ in $\mathrm{H}_{2} \mathrm{O}$ for 5 min gave slightly lower backgrounds than treatment with $3 \% \mathrm{H}_{2} \mathrm{O}_{2}$ in PBS for $30 \mathrm{~min}$. By contrast, the use of $3 \% \mathrm{H}_{2} \mathrm{O}_{2}$ diluted in $40 \% \mathrm{MeOH} / \mathrm{PBS}$ for 15 or 30 min resulted in higher backgrounds, thereby reducing the detection sensitivity. The apparent maximum optimal detection sensitivity for the DENV-2 s/e NS1 glycoprotein was approximately $30 \mathrm{ng} / \mathrm{ml}$ (0.3 ng/dot). The dot-blot assays were therefore apparently more sensitive than Western blot assays; in previous studies using other anti-DENV NS1 glycoprotein-specific MAbs, the maximum sensitivity was obtained with a $10 \mathrm{ng}$ band $[7,21]$.

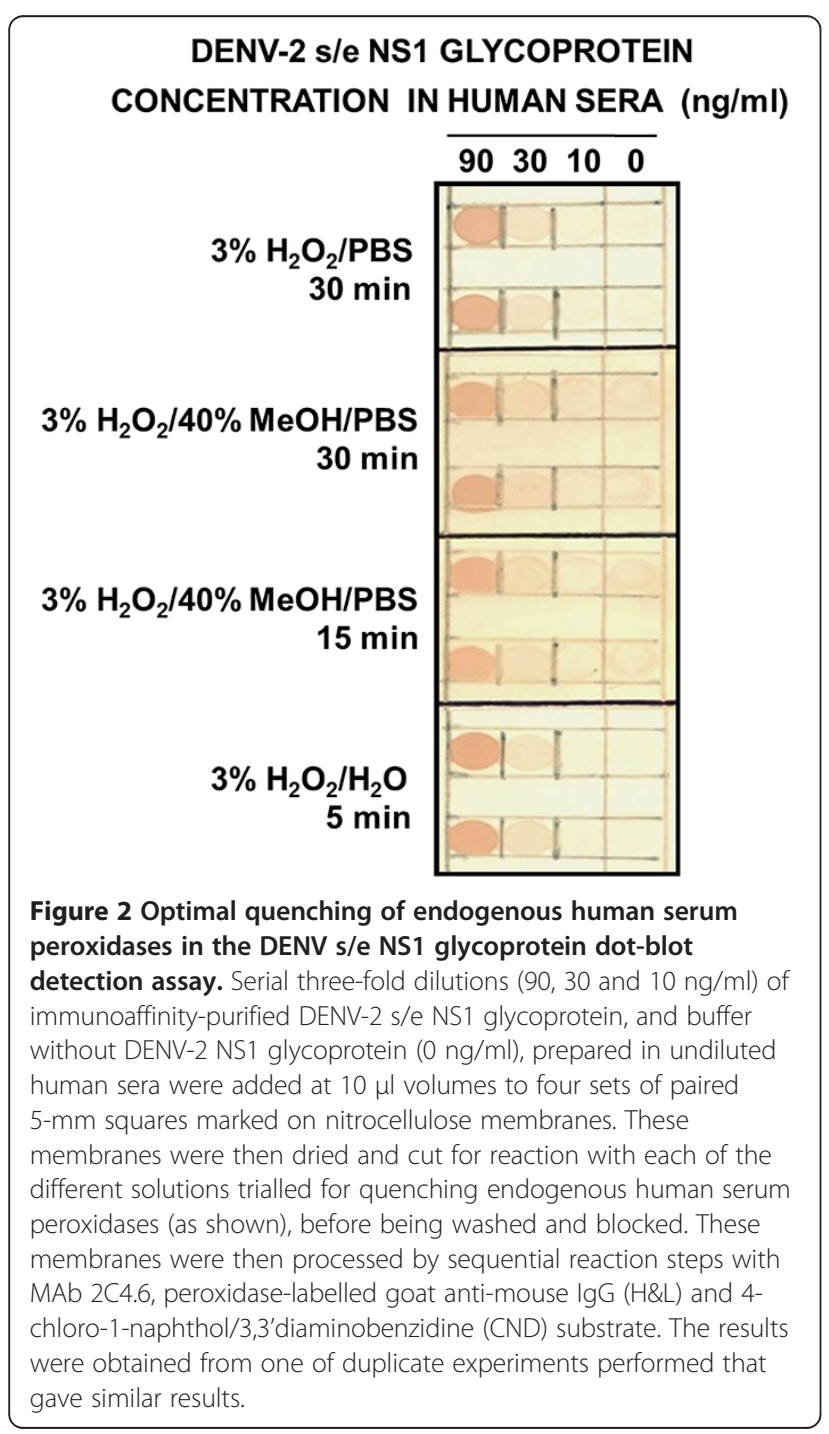

Using the optimal $3 \% \mathrm{H}_{2} \mathrm{O}_{2}$ in $\mathrm{H}_{2} \mathrm{O}$ for 5 min quenching method, with two-fold serial dilutions, the maximum detection sensitivity for the s/e DENV-2 NS1 glycoprotein was $\leq 32 \mathrm{ng} / \mathrm{ml}$ using MAb 2C4.6 (Figure 3). An attempt to improve the sensitivity by the addition of $1 \mathrm{mM} \mathrm{Ni}^{2+}$ to the 4-chloro-1-naphthol/3, 3'diaminobenzidine substrate mixture resulted in reduced DENV s/e NS1 glycoprotein detection sensitivities due to precipitation of the 4-chloro-1-naphthol (data not shown).

Consistent with the inability of MAb 2C4.6 to react with a $35 \mathrm{ng}$ band of the yellow fever virus s/e NS1 glycoprotein in the Western blot assay (Figure 1), this MAb also showed no detectable reaction with $5.12 \mathrm{ng}$ $(512 \mathrm{ng} / \mathrm{ml})$ concentration of this glycoprotein in these dot-blot assays (Figure 3).

\section{Comparison of the reaction of MAb 2C4.6 and 3D1.4 against the s/e NS1 glycoprotein of all four DENV serotypes in dot-blot assays}

The ability of MAb 3D1.4 to react with the s/e NS1 glycoprotein of each DENV serotype in the dot-blot assays was compared to that of MAb 2C4.6. MAb 3D1.4 bound more strongly to the corresponding LX1 epitope synthetic peptide sequence of the DENV-1 NS1 glycoprotein than the corresponding peptide sequences of the other DENV serotype [4], and the DENV-1 NS1 glycoprotein using the Pan-E ELISA on serum samples from DENV-1 infected patients $[9,10]$. In this study, MAb 3D1.4 showed a similar detection sensitivity to MAb

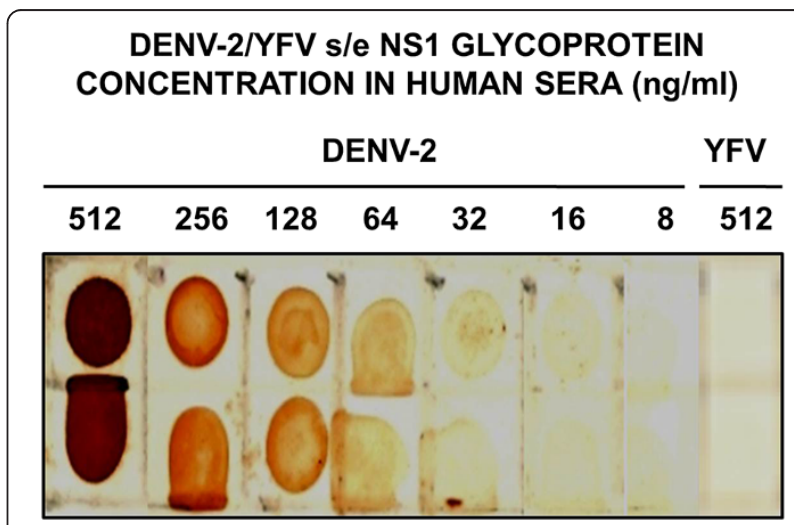

Figure 3 Maximum dot-blot detection sensitivity of MAb 2 C4.6 against the DENV-2 s/e NS1 glycoprotein. Serial two-fold dilutions (512 to $8 \mathrm{ng} / \mathrm{ml}$ ) of immunoaffinity-purified DENV-2 s/e NS1 and YFV s/e NS1 $(512 \mathrm{ng} / \mathrm{ml})$ glycoproteins prepared in undiluted human sera were added at $10 \mu \mathrm{l}$ volumes to paired 5 -mm squares marked on a nitrocellulose membrane. After being dried and treated with $3 \% \mathrm{H}_{2} \mathrm{O}_{2} / \mathrm{H}_{2} \mathrm{O}$ for 5 min to quench the endogenous human serum peroxidases, this membrane was washed and blocked. The membrane was then processed by sequential reaction steps with MAb 2C4.6, peroxidase-labelled goat anti-mouse lgG (H\&L) and 4chloro-1-naphthol/3,3'diaminobenzidine (CND) substrate. The results were obtained from one of duplicate experiments performed that gave similar results. 
2 C4.6 ( $\leq 32 \mathrm{ng} / \mathrm{ml}$ ) against the DENV-1 s/e NS1 glycoprotein, but had lower detection sensitivities against the s/e NS1 glycoprotein of DENV-3 (approximately $64 \mathrm{ng} /$ $\mathrm{ml}$ ), DENV-4 (approximately $100 \mathrm{ng} / \mathrm{ml}$ ), and DENV-2 (approximately $128 \mathrm{ng} / \mathrm{ml}$ ) (Figure 4). Thus, MAb 2C4.6 showed superior detection sensitivity to the s/e NS1 glycoprotein of each DENV serotype than MAb 3D1.4 in these assays.

MAbs 1G5.4-A1-C3 and 1B6.4d, of the IgG2b subclass, also generated against the DENV NS1 glycoprotein showed the same DENV-2 > DENV-4 > DENV-1 > DENV-3 and DENV-2-specific reactions in these dot-blot assays (data not shown) as were observed in Western blot assays, respectively [3,21,22].

Reaction of MAb 2C4.6 with s/e NS1 glycoprotein of each DENV serotype and their stability when dried on nitrocellulose membranes and stored at different temperatures

Serial two-fold dilutions (from 512 to $2 \mathrm{ng} / \mathrm{ml}$ ) of the purified s/e NS1 glycoprotein of each DENV serotype were

\section{DENV s/e NS1 CONCENTRATION IN HUMAN SERA (ng/ml)}

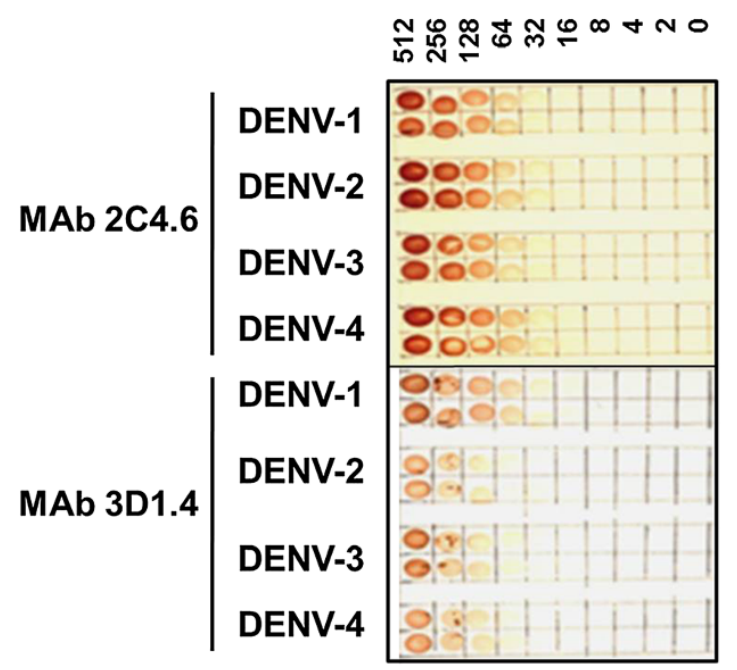

Figure 4 Detection sensitivities of MAb 2C4.6 and MAb 3D1.4 against the s/e NS1 glycoprotein of each DENV serotype. Serial two-fold dilutions from 512 to $2 \mathrm{ng} / \mathrm{ml}$ of immunoaffinity-purified s/e NS1 glycoprotein of each DENV serotype (DENV-1 to DENV-4) or buffer only (0), prepared in undiluted human sera were added at 10 $\mu \mathrm{l}$ volumes to duplicate paired $5-\mathrm{mm}$ squares marked on a nitrocellulose membrane. After being dried and treated with 3\% $\mathrm{H}_{2} \mathrm{O}_{2} / \mathrm{H}_{2} \mathrm{O}$ for 5 min to quench the endogenous human serum peroxidases, this membrane was washed and blocked. After being washed and dried, the membrane was cut into two equal pieces and then processed by sequential reaction steps with either MAb 2C4.6 or MAb 3D1.4, peroxidase-labelled goat anti-mouse IgG (H\&L) and 4-chloro-1-naphthol/3,3'diaminobenzidine (CND) substrate. The results were obtained from one of duplicate experiments performed that gave similar results. prepared in human sera and then added at $10 \mu \mathrm{l} / \mathrm{dot}$ to nitrocellulose membranes. The membranes were dried, quenched for 5 min with $3 \% \mathrm{H}_{2} \mathrm{O}_{2} / \mathrm{H}_{2} \mathrm{O}$, blocked, washed with PBS containing $0.02 \% \mathrm{NaN}_{3}$, and then air dried. After processing, MAb 2C4.6 was observed to bind equally to the s/e NS1 glycoprotein of each DENV serotype, again with a maximum detection sensitivity of $\leq 32 \mathrm{ng} / \mathrm{ml}$ ( $\leq 0.32 \mathrm{ng}$ dot) against each DENV serotype.

We previously observed that s/e DENV NS1 glycoproteins were stable when dried on nitrocellulose membranes in dotblot and Western blot assay formats at ambient temperatures for month-long periods (Falconar, unpublished). The dot-blot assays developed in the current study were also assessed for their stability. The s/e NS1 glycoprotein of each DENV serotype diluted in human sera were quenched for 5 min with $3 \% \mathrm{H}_{2} \mathrm{O}_{2} / \mathrm{H}_{2} \mathrm{O}$, blocked, washed with PBS containing $0.02 \% \mathrm{NaN}_{3}$, air dried, placed in sealed plastic bags and stored for 1 month at ambient temperature (mean: $\left.28^{\circ} \mathrm{C}\right), 4^{\circ} \mathrm{C},-20^{\circ} \mathrm{C}$ or $-80^{\circ} \mathrm{C}$ before processing. After processing them, the detection sensitivity for the NS1 glycoprotein of each DENV serotype remained at $\leq 32 \mathrm{ng} / \mathrm{ml}$ for the membranes stored at $28^{\circ} \mathrm{C}$ and $4^{\circ} \mathrm{C}$ (Figure 5). However, the detection sensitivity for one or more DENV serotypes was reduced for membranes stored at $-20^{\circ} \mathrm{C}$ and $-80^{\circ} \mathrm{C}$.

\section{Reduction of the total dot-blot assay time to 3 hours}

To determine if the dot-blot assay could be performed in $3 \mathrm{~h}$, the same serial dilutions of the s/e NS1 glycoprotein of all four DENV serotypes were used, and the following steps were performed at ambient temperature $\left(28^{\circ} \mathrm{C}\right)$ : i) loading and drying $(40 \mathrm{~min})$, ii) quenching (5 min), iii) washing (0.3 $\mathrm{min})$, iv) blocking (50 min), iv) washing (0.3 min), v) primary MAb (MAb 2C4.6) reaction (30 min), vi) washing ( $\times 1 \mathrm{~min})$, vii) labelled secondary antibody reaction $(25 \mathrm{~min})$, viii) washing $(3 \times 1 \mathrm{~min})$, ix) substrate reaction $(10 \mathrm{~min})$, and $\mathrm{x}$ ) washing $(1 \mathrm{~min})$ (total assay time: $178 \mathrm{~min}$ ). In this study, there was no observable reduction in the maximum DENV-1 to $-4 \mathrm{~s} / \mathrm{e}$ NS1 glycoprotein detection sensitivities of $\leq 32 \mathrm{ng} / \mathrm{ml}$ (Figure 6) compared to those obtained using the longer assay time (Figures 2, 3 and 4); therefore, these simple dot-blot assays could be performed relatively rapidly.

\section{Discussion}

Reaction bias of the MAbs used to detect the DENV s/e NS1 glycoprotein

We previously obtained five MAbs (1A12.3, 3D1.4, 3A5.4, 4H3.4 and 1C6.3), which were used to define DENV complex epitopes on the NS1 glycoprotein [3], and another MAb was generated as a sub-clone (1G5.4-A1-C3) [21]. These MAbs either did not react equally with the s/e NS1 glycoproteins of each DENV serotype in Western blot assays (e.g., MAbs 1 C6.3 and 1G5.4-A1-C3) [5,21,22] or with the corresponding LX1 epitope sequences of each 


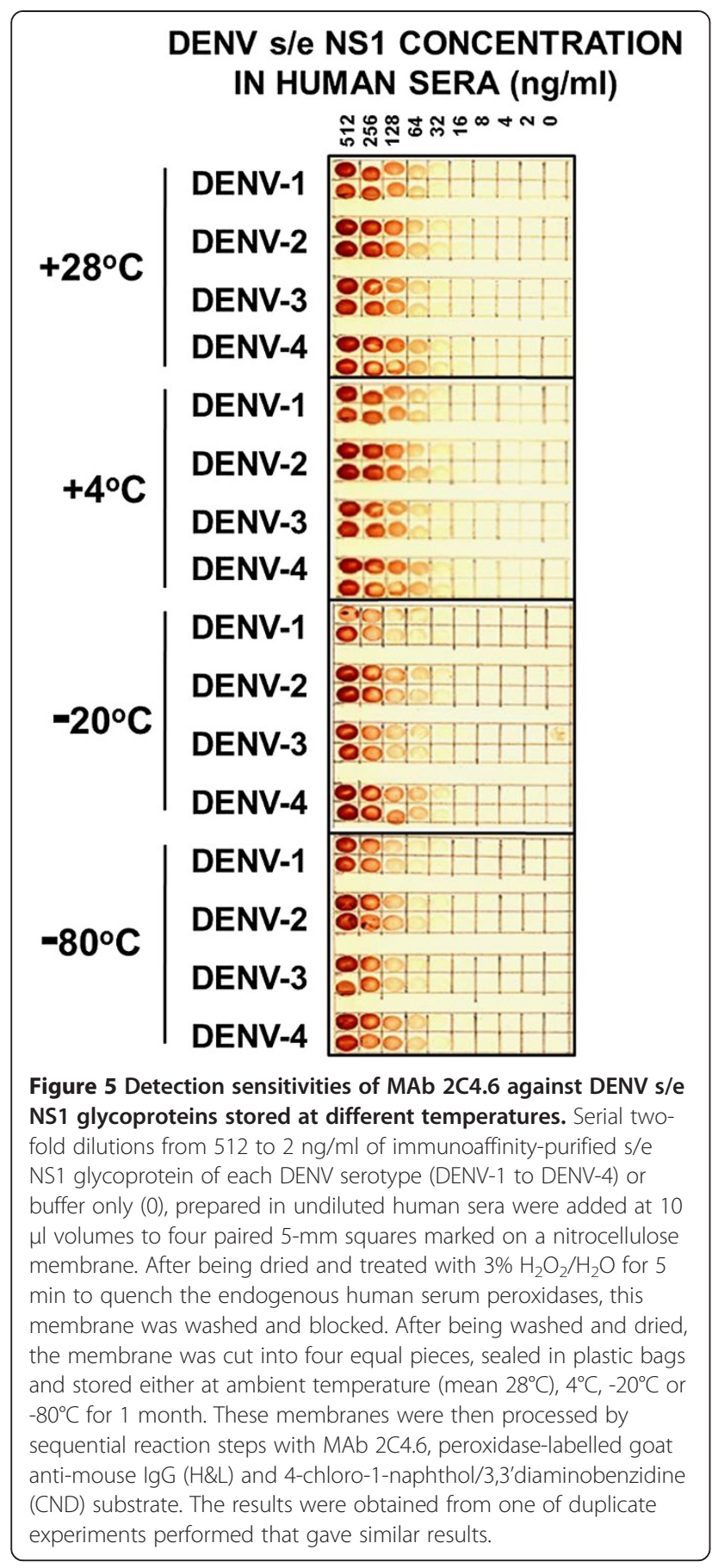

DENV serotype prepared as synthetic peptides (MAbs 3D1.4, 3A5.4, 4H3.4 and 1A12.3) [4]. The present study confirmed that MAb 3D1.4 did not react equally with the s/e NS1 glycoprotein from the different DENV serotypes, showing high sensitivity for the s/e NS1 glycoprotein of DENV-1 $(\leq 32 \mathrm{ng} / \mathrm{ml})$, but lower sensitivity for those of the other serotypes, particularly DENV-2 $(\leq 128 \mathrm{ng} / \mathrm{ml})$ (Figure 4). It is therefore not surprising that the

\section{DENV NS1 gp (ng/ml)}

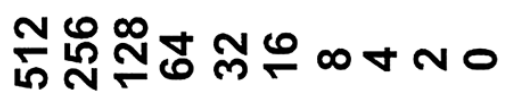

\section{DENV-1

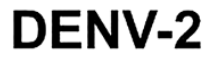

DENV-3

\section{DENV-4}

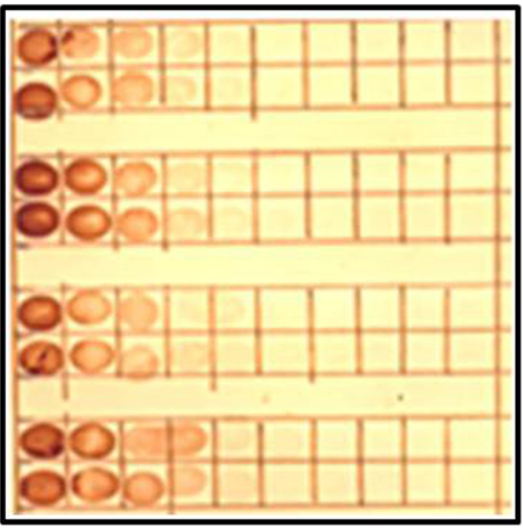

Figure 6 Detection sensitivities of MAb 2C4.6 against the DENV s/e NS1 glycoproteins in a $\mathbf{3} \mathbf{h}$ assay. The maximum detection sensitivity of the assay was assessed against the same serial dilutions of immunoaffinity-purified s/e NS1 glycoproteins when the total dotblot assay time was reduced to $3 \mathrm{~h}$. For this assay, serial two-fold dilutions from 512 to $2 \mathrm{ng} / \mathrm{ml}$ of immunoaffinity-purified s/e NS1 glycoprotein of each DENV serotype (DENV-1 to DENV-4) or buffer only (0), prepared in undiluted human sera were added at $10 \mu \mathrm{l}$ volumes to paired 5-mm squares marked on a nitrocellulose membrane. After being dried and treated with $3 \% \mathrm{H}_{2} \mathrm{O}_{2} / \mathrm{H}_{2} \mathrm{O}$ for 5 min to quench the endogenous human serum peroxidases, this membrane was washed and blocked before being processed by sequential reaction steps with MAb 2C4.6, peroxidase-labelled goat anti-mouse lgG (H\&L) and 4-chloro-1-naphthol/3,3'diaminobenzidine (CND) substrate. The results were obtained from one of duplicate experiments performed that gave similar results.

commercially-available DENV s/e NS1 glycoprotein detection assays showed much higher sensitivities with DENV1 infected patients' sera than with sera from patients infected with the other DENV serotypes, particularly DENV-2 and DENV-4 [9-11,14]. This suggests that these assays all employ MAbs binding to the LX1 epitope. We attempted to generate better MAbs by immunising BALB/ $\mathrm{c}$ mice with a mixture of s/e NS1 glycoproteins from each DENV serotype, screening resultant hybridomas against known concentrations of these glycoproteins using ELISAs, preparative Western blot strips, and dot-blot assays.

\section{Sensitivity of the DENV s/e NS1 glycoprotein assays}

Our simple dot-blot assays showed maximum sensitivities of $\leq 32 \mathrm{ng} / \mathrm{ml}$, more than adequate to detect concentrations of s/e NS1 glycoproteins from DENV-1 and DENV-3 (from 43 to $15219 \mathrm{ng} / \mathrm{ml}$ ) that were detected 
in patient sera using the Platelia ELISA [15]. In contrast, the Platelia assay could only detect low concentrations $(2-163 \mathrm{ng} / \mathrm{ml})$ of the s/e NS1 glycoprotein in sera from patients infected with DENV-2. Indeed, the DENV-2 s/e NS1 glycoprotein was undetectable in one-third of these patients, despite levels of viremia similar to those infected with DENV-1 and DENV-3 [15]. These observations indicate that the DENV-2 s/e NS1 glycoprotein was poorly detected by the MAb used in this assay. This was strongly supported by detection of DENV-2 s/e NS1 glycoprotein in $71 \%(10 / 14)$ and $89 \%(16 / 18)$ of patients who subsequently developed DF and DHF, respectively, and their high concentrations of the s/e NS1 glycoprotein (up to $14000 \mathrm{ng} / \mathrm{ml}$ ) and high virus titres (viraemias) [23], similar to those in DENV-1 and DENV3 infected patients [15]. In contrast to the Platelia assay, this non-commercially developed capture ELISA incorporated a DENV-2 NS1 glycoprotein-specific MAb, 1H7, along with rabbit anti-DENV-2 NS1 glycoprotein PAbs $[3,6,23]$. Importantly, this non-commercial assay detected the DENV-2 s/e NS1 glycoprotein at $>600$ $\mathrm{ng} / \mathrm{ml}$ in $21 \%(3 / 14)$ and $72 \%(13 / 18)$ of the patients who subsequently developed DF and DHF, respectively, thereby providing a sensitivity of $72 \%$ and a specificity of $79 \%$ for identifying patients who subsequently developed SDD (DHF/DSS) [23]. However, unlike the DENV-2 NS1 glycoprotein specific MAb $1 \mathrm{H} 7.4$ and the MAbs used in commercial DENV s/e NS1 glycoprotein detection assays, MAb 2 C4.6 reacted equally with the s/e NS1 glycoproteins of each DENV serotype in human serum samples.

\section{Effect of patient PAbs on DENV s/e NS1 glycoprotein detection assays}

Both the Platelia and Pan-E detection ELISAs showed markedly reduced sensitivity when used to test sera from patients with secondary DENV-2 infections compared with sera from patients with primary DENV-2 infections [24]. Furthermore, the presence of anti-DENV IgM and, to a much greater extent, anti-DENV IgG PAbs, in sera from Vietnamese patients reduced the sensitivity of the Platelia assay [13]. Thus, the combination of MAbs that do not react equally with the s/e NS1 glycoproteins of each DENV serotype and the presence of patient PAbs against the DENV NS1 glycoproteins (generated during secondary DENV infections) is likely to be responsible for the low sensitivity of these commercial assays. The incorporation of simple acid treatment and neutralisation steps, which disrupt circulating immune complexes (CICs) present in the patient sera, improved the detection of the DENV s/e NS1 glycoprotein (particularly in patients infected with DENV-2) in dot-blot assays of acute-phase primary and secondary sera from Indonesian patients [17]. While these acid treatment and neutralisation steps had little effect on the sensitivity to the DENV-1, DENV-3 and DENV-4 s/e NS1 glycoproteins (although only one DENV-4-infected patient was tested), they markedly increased the detection of the DENV-2 s/e NS1 glycoprotein in infected patient sera from $25 \%$ to $100 \%$ [17]. In contrast, only a modest increase in sensitivity (9\%) was reported when these acid treatment and neutralisation steps were performed on patient sera prior to testing in the Platelia assay; however, the DENV serotypes in those patients had not been determined [25]. The weak reaction between MAb 3D1.4 and the s/e NS1 glycoprotein of DENV-4 in the dot-blot assays observed in the current study (Figure 4) was consistent with the lower detection rates observed when the commercial assays were used to test acute-phase sera from patients infected with DENV-4 [9-11,14]. Further studies are needed to assess whether these acid treatment and neutralisation steps are more suited to improving the detection of the DENV-2 and DENV-4 s/e NS1 glycoproteins present in patient CICs in the dot-blot assays, as they bind more rapidly to nitrocellulose membranes after neutralisation than they do in the capture ELISAs where such delays may result in the reformation of CICs. Acid treatment of patient sera for the DENV s/e NS1 glycoprotein detection dot-blot assays was however performed for 60 minutes before neutralization [17], thereby adding additional time to the assay. This would have also dissociated the DENV NS1 glycoproteins into their monomeric forms [7]. Alternative agents that disrupt patient CICs more quickly are likely to be useful in these assays (see below).

\section{Combination of single-patient DENV-specific IgM/lgG and DENV s/e NS1 glycoprotein detection results for DENV diagnosis}

The sensitivity of commercial assays is reportedly increased by combining results from DENV NS1 glycoprotein assays with those from anti-DENV-specific pre-membrane (prM) and envelope (E) (prM/E) glycoprotein IgG and/or IgM detection assays [10-12,26]. However, false-positives have been reported using some DENV NS1 glycoprotein or anti-DENV prM/E glycoprotein IgG or IgM antibody detection assays during secondary DENV infections or with sera from patients carrying other infectious agents or from healthy donors [10-12]. These false-positives may account for the reported increased sensitivity of such combined assays, in addition to the use of sera from patients predominantly infected with DENV (DENV-1 or DENV-3) serotypes, more easily detected by these commercial assays: a) DENV-1 (DENV-1: 56.3\%; DENV-2: 37.6\%; DENV-3: 6.6\%; DENV-4: 0.0\%) [26]; b) DENV-1 plus undetermined DENV serotypes (DENV-1: 39.3\%; DENV-2: 16.3\%; DENV-3: 6.3\%; DENV-4: 8.4\%; undetermined DENV serotypes: 29.7\%) [11]; or c) DENV-3 plus 
undetermined DENV serotypes (DENV-1: 1\%; DENV-2: 16.2\%; DENV-3: 47.5\%; DENV-4: 2.0\%; undetermined: 33.3\%) [12]. Importantly, some DENV patients (termed "LS patients) generated low levels of anti-DENV prM/E glycoprotein reactive IgG antibodies, even during secondary DENV infections [19]. Indeed, $40 \%$ of patient sera may be negative for IgG and IgM antibodies against the DENV $\mathrm{E}$ and prM glycoproteins on day 3 after the onset of fever [19], and DENV prM/E glycoprotein-specific IgM antibodies were not generated during secondary DENV infections in patients from either Asia (28\% IgM-negative) [27] or the Americas (33\% IgM-negative) [19]. These problems were further confirmed by the very low sensitivity observed for a commercially-available combined DENV diagnostic assay used to test a panel of sera from patients with fully characterised DENV infections, primarily secondary DENV-2 or DENV-4 infections [Falconar and Romero-Vivas, unpublished]. DENV-2 and DENV-4 are the dominant DENV serotypes in our DHF/DSS-endemic study site in the Americas (Colombia) [19,20]. These serotypes were maintained in the Americas after their introduction [28,29] and are important causes of DENV epidemics (e.g. in Mexico [30], Nicaragua [31], Guatemala and Honduras [32], Brazil [33]) and the Caribbean islands (e.g., Martinique [34]), as well as in Asia (e.g., Thailand [35], Singapore [36] and China [37]). Thus, there is an urgent need to develop simple, inexpensive, sensitive and robust NS1 glycoprotein detection assays that can equally detect the s/e NS1 glycoprotein of each DENV serotype.

\section{Advantages of DENV s/e NS1 glycoprotein detection dot- blot assays using improved MAbs}

The failure to maintain DENV patient sera at low temperatures before testing resulted in an inability to detect the glycoprotein in acute-phase sera from patients with primary DENV-2 infections [6]. Thus, the ability to store antigenically stable prepared membranes at $28^{\circ} \mathrm{C}$ (Figure 5), is highly desirable. These membranes can then be immediately processed using basic equipment and reagents, and by staff with minimal training. Alternatively, they can be transferred to other laboratories at ambient temperatures for processing. As a result, large numbers of samples from patients with febrile illnesses can be screened easily, inexpensively (approximately US \$ 0.05/sample, i.e., 100-200 times less expensive than commercial detection assays) and relatively rapidly for DENV infections in all endemic areas. Importantly, simple definitive clinical criteria (conjunctival injection, abdominal pain and venipuncture bleeding) can also be applied to patients by staff from such clinics with minimal training, to identify the relatively low numbers of DENV-infected patients who will subsequently develop SDD (DHF/DSS), so that prompt hospital-based therapy can be provided [19].

\section{Conclusions}

This is the first study to assess quantitatively the sensitivity of a DENV NS1 glycoprotein detection assay using known concentrations of s/e NS1 glycoprotein from each DENV serotype. The main findings were that: i) hybridomas were generated and successfully screened for MAbs that showed an equally strong reaction with purified s/e NS1 glycoprotein of each DENV serotype; ii) optimal quenching of endogenous peroxidases in human sera was achieved using $3 \% \mathrm{H}_{2} \mathrm{O}_{2}$ (in $\mathrm{H}_{2} \mathrm{O}$ ) for 5 min; iii) the maximum sensitivity of MAb $2 \mathrm{C} 4.6$ for the s/e NS1 glycoprotein of each DENV serotype was $\leq 32 \mathrm{ng} /$ $\mathrm{ml}(\leq 0.32 \mathrm{ng} / \mathrm{dot})$; iv) the addition of $1 \mathrm{mM} \mathrm{Ni}^{\overline{2}+}$ to the substrate mixture reduced the sensitivity of the dot-blot assays; v) s/e NS1 glycoproteins of each DENV serotype in human sera were stable when dried on nitrocellulose membranes at ambient temperature $\left(28^{\circ} \mathrm{C}\right)$ or when stored at $4^{\circ} \mathrm{C}$ for at least 1 month before processing; vi) the total assay time was reduced to $3 \mathrm{~h}$ without any loss of sensitivity; vii) the estimated cost of these assays was US\$ $0.05 /$ sample, and vii) the sensitivity of MAb 2 C4.6 for the s/e NS1 glycoprotein of the DENV-2, DENV-3 and DENV-4 serotypes was superior to that of MAb 3D1.4 in these assays.

Dot-blot assays, such as the one developed here, have the potential for use as simple, robust, inexpensive and relatively rapid diagnostic tools in DENV-endemic countries, where there are an estimated 50-100 million infections annually [1].

\section{Further studies}

We are presently testing whether improved alternative methods for disruption of patient CICs together with alternative detection methods can be used to increase the sensitivities of these dot-blot assays by 10 to 100 -fold and to reduce the total assay time to the same (or less) than that required to perform the Pan-E, Platelia and Standard Diagnostic DENV NS1 glycoprotein detection ELISAs (2.5 hours).

We also wish to fully evaluate these dot-blot assays using large numbers of patient sera collected during the acute phase of primary and secondary DENV infections caused by each DENV serotype (i.e. $\mathrm{n} \geq 200$ ) which have been typed by full IgM/IgG ELISA titrations and DENV isolation followed by serotype determinations, together with full clinical details $[19,20]$. Since some commercial DENV s/e NS1 detection assays have also been shown to give false positives using normal human sera, and sera from patients with some other viral or bacterial diseases [11], we will also determine whether MAb 2C4.6 will not generate such false positive reactions in these assays. If these studies are successful, MAb 2C4.6 may be suitable for use in a rapid (5-10 $\mathrm{min})$ point-of-care format. 


\section{Materials and Methods Ethics statement}

The collection of $5 \mathrm{ml}$ blood samples from two clinically healthy human volunteers to obtain the normal human sera used in this study was approved by the University del Norte Ethics Committee. All animal experiments were approved by the Universidad del Norte Ethics Committee following the guidelines for the care and use of experiment animals established by the Colombian government, and following NIH guidelines.

\section{Study site}

Barranquilla is the principal seaport of Colombia and lies at the mouth of the Magdalena River on the Caribbean coast. All four DENV serotypes have become endemic in the city, with severe dengue disease (SDD: DHF/DSS) being confirmed since 1997. The isolation of all four DENV serotypes of DENV (DENV-1 (S\#14 strain), DENV-2 (S\#42 strain), DENV-3 (S\#25 strain) and DENV-4 (S\#10 strain) in insect (C6/36) cells was performed as described previously $[19,20]$.

\section{Purification of MAbs and preparation of immunoaffinity columns}

The purification of mouse MAbs of the IgG1, IgG2a and IgG2b subclasses and the preparation of immunoaffinity columns were carried out as described previously $[3,21,22]$. MAb 3A5.4 was used for these studies due to its ability to react with the s/e NS1 glycoproteins of each DENV serotype, as well as the s/e NS1 glycoprotein of YFV. Briefly, highly concentrated stocks of MAb 3A5.4 were diluted in phosphate buffered saline (PBS) ( $\mathrm{pH}$ 7.6) and slowly passed through a protein G-Sepharose (P3296, Sigma-Aldrich, USA) column, washed with PBS, eluted using $0.1 \mathrm{M}$ glycine $/ \mathrm{HCl}(\mathrm{pH} 2.5)$, and $0.9-\mathrm{ml}$ fractions were immediately neutralised with $100 \mu \mathrm{l}$ of $2 \mathrm{M}$ Tris/HCl (pH 7.8). High-MAb-containing fractions were identified using the bicinchoninic acid (BCA) protein assay (BCA-1, Sigma-Aldrich, USA), pooled and repeatedly dialysed against 2 litre volumes of $0.2 \mathrm{M}$ $\mathrm{NaHCO}_{3} / 0.5 \mathrm{M} \mathrm{NaCl}$ ( $\mathrm{pH}$ 8.9). Cyanogen-bromideactivated Sepharose 4B (0.8 g) (C9142, Sigma-Aldrich, USA) was pre-swollen and then washed with $500 \mathrm{ml}$ of ice-cold $\mathrm{HCl}(1 \mathrm{mM})$. MAb 3A5.4 (12-15 mg) in $5 \mathrm{ml}$ of the dialysate was then added, and the capped columns were incubated by inversion overnight at $4^{\circ} \mathrm{C}$. The excess sites were then blocked with $1 \mathrm{M}$ ethanolamine $/ \mathrm{PBS} / \mathrm{HCl}$ ( $\mathrm{pH}$ 9.0) for $2 \mathrm{~h}$ at ambient temperature. These columns were then subjected to nine cycles of high and low $\mathrm{pH}$ oscillations using $0.1 \mathrm{M}$ glycine $/ \mathrm{HCl}$ containing $1 \mathrm{M}$ $\mathrm{NaCl}(\mathrm{pH} 3.5)$ and $50 \mathrm{mM}$ Tris $/ \mathrm{HCl}$ containing $1 \mathrm{M}$ $\mathrm{NaCl}$ ( $\mathrm{pH}$ 9.0), before being washed with $10 \mathrm{mM}$ diethylamine/PBS (pH 11.2) and then PBS containing $0.2 \%$ (wt/vol) $\mathrm{NaN}_{3}$ before being stored at $4^{\circ} \mathrm{C}$.

\section{Growth of DENV strains of each DENV serotype and YFV and the immunoaffinity purification of their s/e NS1 glycoproteins}

DENV strains of all four DENV serotypes were propagated in both insect (C6/36) cell and mammalian (Vero) cell monolayers as described previously $[5,19]$. For these studies, YFV (17D-204 vaccine strain) was also propagated in both C6/36 and Vero cells. High-titre seed stocks of each virus were prepared in $80 \mathrm{~cm}^{2}$ cultures of $70 \%$ confluent C6/36 cells maintained in Leibovitz L-15 medium (L4386, Sigma-Aldrich, USA) containing 10\% (vol/vol) tryptose phosphate broth (T9157, SigmaAldrich, USA) with $10 \%$ (vol/vol) foetal calf serum (FCS), pyruvate, L-glutamine and antibiotics (referred to hereafter as insect cell growth medium (ICGM)). Cell culture supernatants were collected on days 4 and 8 after infection, clarified by centrifugation and stored at $80^{\circ} \mathrm{C}$. These stocks were used to infect $70 \%$-confluent mammalian (Vero) cell monolayers maintained in medium 199 containing $\mathrm{Na}_{2} \mathrm{HCO}_{3}, 3.5 \%$ FCS, pyruvate, L-glutamine and antibiotics (referred to hereafter as mammalian cell growth medium (MCGM) in 10 large $\left(225 \mathrm{~cm}^{2}\right)$ flasks. After growth at $37^{\circ} \mathrm{C}$ in a $5 \%(\mathrm{vol} / \mathrm{vol})$ $\mathrm{CO}_{2}$ atmosphere for 4 days, the supernatants were collected and replaced by fresh MCGM and incubated for a further 4 days before being harvested. These supernatants were made up to $20 \mathrm{mM}$ Tris/ $\mathrm{HCl}(\mathrm{pH} 7.4), 1 \mathrm{mM}$ PMSF, 5 mM Na 2 EDTA, 0.05\% (wt/vol) $\mathrm{NaN}_{3}, 7 \%$ (wt/ vol) polyethylene glycol 8000 (89510, Sigma-Aldrich, USA) and 0.4 M NaCl using stock solutions. The DENV particles (virions) were then allowed to aggregate overnight at $4^{\circ} \mathrm{C}$ before being removed by centrifugation at $8,000 \times g$ for $30 \mathrm{~min}$ at $4^{\circ} \mathrm{C}$. The clarified supernatants were then slowly $(1 \mathrm{ml} / \mathrm{min})$ passed through the MAb 3A5.4 or 3D1.4 immunoaffinity columns. After washing with loading buffer, the bound extracellular/secreted (s/e) NS1 glycoproteins were eluted in their native homo-hexameric form using $20 \mathrm{mM}$ diethylamine in $10 \mathrm{mM}$ Tris/ $\mathrm{HCl}$ containing $150 \mathrm{mM} \mathrm{NaCl}$, PMSF and EDTA and $0.4 \mathrm{ml}$ fractions were immediately neutralised with $100 \mu \mathrm{l}$ of $1 \mathrm{M}$ Tris/ $\mathrm{HCl}$ ( $\mathrm{pH}$ 7.2). Protein concentrations were determined in ELISA plates using $10 \mu \mathrm{l}$ of sample in $200 \mu \mathrm{l}$ of BCA reagent (BCA-1, Sigma-Aldrich, USA) with standard concentrations $(16 \mathrm{mg} / \mathrm{ml}$ to $125 \mu \mathrm{g} / \mathrm{ml}$ serial dilutions) of bovine serum albumin (A7906: Sigma, USA) concentrations prepared in neutralised elution buffer. ELISA plates were incubated at $37^{\circ} \mathrm{C}$ for $60 \mathrm{~min}$ and then absorbance was determined at $570 \mathrm{~nm}$ (MRX, Dynax, USA), and protein concentrations were derived from the standard curves. Fractions containing the DENV s/e NS1 glycoproteins were concentrated by centrifugation dialysis at 1,000-2,000 $\times g$ (Centricon 10, Amersham, UK) against RPMI-1640 medium (R6504, Sigma, USA) containing a cocktail of protease inhibitors 
(P1860, Sigma-Aldrich, USA). Protein concentrations were then determined again and fractions were stored at $-80^{\circ} \mathrm{C}$.

One $25 \mathrm{~cm}^{2}$ flask of DENV-2 infected Vero cells was also used to prepare an infected cell lysate for the Western blot assays by discarding the supernatant and repeatedly washing the cells with RPMI medium before the addition of $2 \mathrm{ml}$ of $32 \mathrm{mM}$ orthophosphoric acid/58 $\mathrm{mM}$ Tris base (pH 6.7) (345245/T6066: Sigma-Aldrich, USA) containing $10 \%$ sodium dodecyl sulphate (SDS) (L3771, Sigma, USA) (cell-lysis buffer). After repeated passage through a 23-gauge needle to break the DNA, the cell lysate was centrifuged at $200 \times g$ and aliquots of the supernatant were stored at $-80^{\circ} \mathrm{C}$.

\section{Immunisation of mice and production of mouse MAbs}

The immunisation and use of halothane in oxygen to anaesthetise $\mathrm{BALB} / \mathrm{c}$ mice, and the production and cloning of MAbs were carried out as described previously $[5,22,38]$. Briefly, a group of three 6-week-old female BALB/c mice (Universidad Nacional, Bogota, Colombia) were immunised by the combined subcutaneous (s.c.; 0.1 $\mathrm{ml}$ ) and intra-peritoneal (i.p.; $0.4 \mathrm{ml}$ ) routes with a mixture of $5 \mu \mathrm{g}$ of the purified e/s NS1 glycoprotein of each DENV serotype (i.e., $20 \mu \mathrm{g} /$ mouse) emulsified in complete Freund's adjuvant (F5881, Sigma, USA). These mice were also each injected with $0.5 \mu \mathrm{g}$ of mouse interleukin-12 (IL-12) by the i.p. route on days $1,3,5$ and 7 after the immunisations to increase the production of PAbs of the IgG2a subclass [39]. Three weeks later, the mice were boosted with the sample antigen emulsified in incomplete Freund's adjuvant (F5506: Sigma, USA) at the same dose and via the same route, and they also received the same multiple IL-12 injections. Four weeks later, the mice were anaesthetised and blood samples were obtained from the retro-orbital sinus. The highest responding mouse, as determined by the indirect ELISA titres against the s/e NS1 glycoprotein of each DENV serotype, was then immunised with $10 \mu \mathrm{g}$ each of the DENV-1 (S\#14 strain), DENV-2 (S\#42 strain), DENV-3 (S\#25 strain) and DENV-4 (S\#10 strain) s/e NS1 glycoproteins ( $40 \mu \mathrm{g}$ in total) in RPMI medium by the combined intravenous (i.v.) route in the tail vein $(100 \mu \mathrm{l})$ and the i.p. route $(300 \mu \mathrm{l})$. Three days later, this mouse was anesthetised and humanely killed by cervical dislocation, immersed in $70 \%$ ethanol and transferred to a class II laminar flow cabinet. The spleen cells were aseptically removed in RPMI medium containing $10 \%$ MAb-cloning tested quality FCS (FCS Premium: Biomeda, USA) and then centrifuged at $200 \times g$ for 10 min at $28^{\circ} \mathrm{C}$. SP2/0 Ag14 plasmacytoma cells (ATCC, USA), grown in RPMI medium containing 20\% FCS and pyruvate, L-glutamine and antibiotics (PGAB), were harvested. The spleen and plasmacytoma cells were counted and mixed at a 10:1 ratio, co-centrifuged at $250 \times g$ and the supernatant was discarded. One millilitre of $45 \%$ (wt/vol) polyethylene glycol 4000 (Merck $\mathrm{BDH}, \mathrm{UK}$ ) containing 5\% dimethylsulfoxide (D2650, Sigma, USA)/PBS ( $\mathrm{pH}$ 8.1) was slowly added to the loosened cell pellet over a period of 1 min with constant agitation before being slowly diluted with $20 \mathrm{ml}$ of Hank's balanced salt solution (H9394, Sigma, USA). After incubation at $28^{\circ} \mathrm{C}$ for $30 \mathrm{~min}$, the cells were pelleted by centrifugation at $200 \times g$, the supernatant was discarded, and the cells re-suspended in $200 \mathrm{ml}$ of RPMI medium containing 20\% FBS, $1 \times$ HAT (H0262: Sigma, USA) and PGAB before being added to 96-well culture plates (NUNC, USA) at $200 \mu \mathrm{l} /$ well. After incubation at $37^{\circ} \mathrm{C}$ in $5 \% \mathrm{CO}_{2} /$ air for 5 days, $100 \mu \mathrm{l}$ of the medium was changed and thereafter $150 \mu \mathrm{l}$ was changed every 3 days until the DENV s/e NS1 glycoprotein MAb-positive wells were expanded. The 150 $\mu \mathrm{l}$ volumes collected from each well were tested by ELISA for reactions against the purified DENV s/e NS1 glycoprotein of each DENV serotype, and the contents of the wells containing MAbs that cross-reacted with the s/e NS1 glycoprotein of multiple DENV serotypes were transferred into 48-well plates (Costar, USA). HAT selection medium was subsequently substituted with medium containing HT (H0137, Sigma, USA) after 14 days, from which these hybridomas were never weaned. The culture supernatants were then tested for reactivity with the s/e NS1 glycoprotein from each DENV serotype in dot-blot assays. Western blot assays were also performed to test reactivity against a) the NS1 glycoproteins from each DENV serotype and YFV, b) the 2-mercaptoethanol reduced DENV-2 s/e NS1 glycoprotein, the cell-associated DENV-2 NS1 glycoprotein present in a crude SDS-lysate of DENV-2 infected Vero cells, and c) the DENV-2 s/e NS1 glycoprotein present in a human serum sample after the sera had been treated with $3 \% \mathrm{H}_{2} \mathrm{O}_{2}$ /PBS for 30 min to quench endogenous peroxidases. Thus, these assays were used to select wells containing hybridomas that secreted MAbs that specifically reacted with the s/e NS1 glycoprotein of each DENV serotype, and which would not cross-react with proteins in Vero cells or human sera.

Hybridomas that secreted the desired MAbs were cloned twice by limiting dilution in 96-well cell culture plates containing $2-4 \times 10^{4} /$ well CD1 (Swiss out-bred) mouse peritoneal macrophage feeder layers. Single wells were identified using an inverted microscopy, the supernatants were screened by ELISA against DENV s/e NS1 glycoproteins and the resultant cloned hybridomas were further sequentially expanded and harvested, pelleted by centrifugation and the cells slowly $\left(-1^{\circ} \mathrm{C} / \mathrm{min}\right)$ frozen to $80^{\circ} \mathrm{C}$ after being re-suspended in ice-cold $10 \%$ (vol/vol) DMSO/FCS, before being transferred to liquid nitrogen. From this fusion, MAb $2 \mathrm{C} 4.6$ and a number of other cloned hybridomas were selected. 
The IgG subclass of the MAbs was determined by a kit using goat PAbs specific for each mouse IgG subclass in radial immunoassays (ISO-2, Sigma, USA), according the manufacturer's instructions.

\section{Immunoassays}

The indirect DENV s/e NS1 glycoprotein ELISA was performed as described previously [5,21,23]. Briefly, the immunoaffinity-purified DENV-2 s/e NS1 glycoproteins (see above) or the negative-control antigen, bovine serum albumin, were diluted to $3 \mu \mathrm{g} / \mathrm{ml}$ in carbonate/bicarbonate buffer ( $\mathrm{pH}$ 9.8), loaded into 96-well ELISA plates (Immulon 2, Dynatech, USA) and adsorbed overnight at $4^{\circ} \mathrm{C}$. After washing with PBS containing $0.05 \%$ (vol/vol) Tween20 (PBS/T), blocking with 1\% (wt/vol) gelatin/PBS for $2 \mathrm{~h}$ at $25^{\circ} \mathrm{C}$ and washing again with PBS/ $\mathrm{T}, 50 \mu \mathrm{l}$ volumes of the undiluted hybridoma wells were transferred to each ELISA well and allowed to react at $37^{\circ} \mathrm{C}$ for $60 \mathrm{~min}$. After washing with $\mathrm{PBS} / \mathrm{T}$, the bound MAbs were detected with sequential reaction steps using peroxidase-labelled goat anti-mouse IgG heavy and light $(\mathrm{H} \& \mathrm{~L})$ chain reactive (115-035-166, Jackson ImmunoResearch, USA) in PBS/T/G, washing with PBS/T, incubation with $o$-phenylenediamine (opd) in citrate/phosphate buffer ( $\mathrm{pH}$ 5.0) containing $\mathrm{H}_{2} \mathrm{O}_{2}$ and the absorbance values measured at $490 \mathrm{~nm}$ (MRX: Dynex, USA).

The Western blot assays were performed as described previously $[3,21,22]$. Samples were prepared using $1.0 \mu \mathrm{g}$ s/e NS1 glycoprotein of each DENV serotype added to $160 \mu \mathrm{l}$ of stacking buffer containing $0.5 \%$ (wt/vol) SDS, $32 \mu \mathrm{l}$ of $0.25 \%$ (wt/vol) bromophenol blue in $50 \%$ glycerol $/ \mathrm{H}_{2} \mathrm{O}$, with (all DENV serotypes) or without (DENV-2 s/e NS1 glycoprotein) 1\% (vol/vol) 2mercaptoethanol (M3148: Sigma, USA). In addition, 160 $\mu \mathrm{l}$ of a DENV-2 infected Vero cell lysate (see cell culture) and $30 \mu \mathrm{l}$ of a normal human serum sample (which had been diluted 1 in 4 with PBS) were both treated with $3 \%$ (vol/vol) $\mathrm{H}_{2} \mathrm{O}_{2}$ (H1009, Sigma, USA) for $60 \mathrm{~min}$ at $28^{\circ} \mathrm{C}$ to quench endogenous human serum peroxidases, before the addition of the $5 \times$ stacking buffer and $1.0 \mu \mathrm{g}$ of DENV-2 s/e NS1 glycoprotein (total volume $160 \mu \mathrm{l}$ ). Both were then treated with $32 \mu \mathrm{l}$ of $0.05 \%$ (wt/vol) bromophenol blue in $50 \%$ glycerol $/ \mathrm{H}_{2} 0$. These samples were then heated at $100^{\circ} \mathrm{C}$ for $3 \mathrm{~min}$. After cooling and centrifugation, they were then loaded onto 8-9\% (wt/ vol) preparative SDS/PAGE gels (Miniprotean II: BioRad, UK) and subjected to electrophoresis (15-20 constant $\mathrm{mA} /$ gel) and subsequent electro-blotting at 160 $\mathrm{mA} /$ gel (Sartoblot II, Sartorius, UK) onto $0.2-\mu \mathrm{m}$ poresized nitrocellulose membranes (BioTraceNT, PAL LifeSciences, USA) before being dried. These membranes were then blocked using 3\% (wt/vol) skimmed milk powder (Marvel, Cadbury, UK)/PBS (PBS/T/M) containing $0.02 \%$ (wt/vol) $\mathrm{NaN}_{3}$, washed with $\mathrm{PBS} / \mathrm{T}$, dried and then cut into 3-mm wide strips. Preparative blot strips of the reduced (DENV-2 s/e NS1 glycoprotein only) and nonreduced (s/e NS1 glycoproteins of all DENV serotypes and YFV, DENV-2 infected Vero cells and human sera which contained the DENV-2 s/e NS1 glycoprotein) were taped together with waterproof autoclave tape and allowed to react with $0.5 \mathrm{ml}$ of the MAb supernatants of two $500 \mu \mathrm{l}$ samples (1 ml total) from 48-well cultures diluted with an equal volume of $\mathrm{PBS} / \mathrm{T}$ containing $2 \%$ (wt/vol) skimmed milk powder for $2 \mathrm{~h}$ at ambient temperature. After washing with PBS/T, the bound MAbs were detected using sequential reaction steps with peroxidase-labelled goat anti-mouse IgG (H\&L) (115-035-166: Jackson ImmunoResearch, USA) in PBS/T/G, washing with PBS/T, PBS and then reacting the membranes with 4-chloro-1-naphthol/ 3,3'diaminobenzidine (C8890/D8001, Sigma, USA) (CND) substrate in PBS containing $0.006 \%$ (vol/vol) $\mathrm{H}_{2} \mathrm{O}_{2}$.

For the dot-blot assays, $0.5-\mathrm{cm}$ squares were marked on the nitrocellulose membranes using an $8 \mathrm{~B}$ graphite pencil (Staedtler, Germany). Duplicate, serial, two-fold or threefold dilutions of the immunoaffinity-purified s/e NS1 glycoproteins prepared in normal human sera collected from anti-DENV IgM and IgG-negative patients [19] were added at $10 \mu \mathrm{l} /$ dot and were air dried. Different methods were assessed to quench the endogenous peroxidases in the human sera present on these dot-blots. For this study, solutions of $3 \% \mathrm{H}_{2} \mathrm{O}_{2}$ diluted from a $30 \%$ (vol/vol) stock solution (H1009, Sigma Aldrich, USA) in 40\% (vol/vol) $\mathrm{MeOH} / \mathrm{PBS}, \mathrm{PBS}$ or $\mathrm{H}_{2} \mathrm{O}$ were tested. These dot-blot assays were then processed as described for the Western blot assays to identify the detection sensitivities of MAb 2C4.6 against the s/e NS1 glycoprotein of each DENV serotype when reacted at a concentration of 5$10 \mu \mathrm{g} / \mathrm{ml}$ with serial dilutions of each of them. The sensitivities of MAb 2C4.6 and 3D1.4 against known concentrations of the s/e NS1 glycoprotein of each DENV serotype were then compared. The reactions of other MAbs anti-NS1 MAbs (1G5.4-A1-C3 and 1B6.3) of the IgG2b subclass, which defined a DENV-2 > DENV$4>$ DENV-1 > DENV-3 and DENV-2-specific responses against the s/e NS1 glycoprotein of each DENV serotype in Western blot assays respectively [3,21,22], were also tested for their reactions in these dot-blot assays.

In addition, we assessed whether: a) $1 \mathrm{mM} \mathrm{Ni}^{2+}\left(\mathrm{NiCl}_{2}\right)$ could increase the sensitivities of these assays when added to the 4-chloro-1-naphthol/3,3' diaminobenzidine (CND) substrate mixture; b) the assays could be successfully processed without loss of detection sensitivities after sample addition and blocking, washing with PBS containing $0.01 \% \mathrm{NaN}_{3}$ and storing after drying for 1 month at $28^{\circ} \mathrm{C}$ (ambient temperature), $4^{\circ} \mathrm{C},-20^{\circ} \mathrm{C}$ and $-80^{\circ} \mathrm{C}$; and c) the total assay time could be reduced to $3 \mathrm{~h}$ without significant loss of detection sensitivity when they were performed at ambient temperature. 


\section{Competing interests}

The authors declare that they have no competing interests.

\section{Authors' contributions}

The authors both contributed to the design of the experiments, the laboratory work and preparation of the article. Both authors read and approved the final manuscript.

\section{Acknowledgements}

We thank Francis Slater and Francis Donnelly (Bioedit,UK) and Graham Miles (Global Science Editing, UK) for comprehensive editing this article and Andres Tovar and Karolay Garavito-García (Universidad del Norte) for help with the preparation of figures. We also thank two anonymous reviewers the Virology Journal editor Juliano Bordignon for their helpful comments. This study received financial support from the Universidad del Norte (Proyecto Estrategico) and the Departamento Adminstrativo de Ciencias, Technologia e Innovacion (COLCIENCIAS), project number 1215-04-14364.

Received: 9 November 2012 Accepted: 17 April 2013

Published: 22 April 2013

\section{References}

1. World Health Organization: Dengue and severe dengue. Fact Sheet No. 117, January 2012. (http://www.who.int/mediacentre/factsheets/fs117/en/) (accessed 20 ${ }^{\text {th }}$ October 2012)

2. Flamand M, Megret F, Mathieu M, Lepault J, Rey FA, Deubel V: Dengue virus type 1 nonstructural glycoprotein NS1 is secreted from mammalian cells as a soluble hexamer in a glycosylation-dependent fashion. J Virol 1999, 73:6104-6110.

3. Falconar AK, Young PR: Production of dimer-specific and dengue virus group cross-reactive mouse monoclonal antibodies to the dengue 2 virus non-structural glycoprotein NS1. J Gen Virol 1991, 72:961-965.

4. Falconar AKI, Young PR, Miles MA: Precise location of sequential dengue virus subcomplex and complex B cell epitopes on the nonstructural-1 glycoprotein. Arch Virol 1994, 137:315-326.

5. Falconar AK: Monoclonal antibodies that bind to common epitopes on the dengue virus type 2 nonstructural- 1 and envelope glycoproteins display weak neutralizing activity and differentiated responses to virulent strains: implications for pathogenesis and vaccines. Clin Vaccine Immunol 2008, 15:549-561.

6. Young PR, Hilditch PA, Bletchly C, Halloran W: An antigen capture enzymelinked immunosorbent assay reveals high levels of the dengue virus protein NS1 in the sera of infected patients. J Clin Microbiol 2000, 38:1053-1057.

7. Falconar AK, Young PR: Immunoaffinity purification of native dimer forms of the flavivirus non-structural glycoprotein, NS1. J Virol Methods 1990, 30:323-332.

8. Alcon S, Talarmin A, Debruyne M, Falconar A, Deubel V, Flamand M: Enzyme-linked immunosorbent assay specific to Dengue virus type 1 nonstructural protein NS1 reveals circulation of the antigen in the blood during the acute phase of disease in patients experiencing primary or secondary infections. J Clin Microbiol 2002, 40:376-381.

9. Bessoff K, Delorey M, Sun W, Hunsperger E: Comparison of two commercially available dengue virus (DENV) NS1 capture enzyme-linked immunosorbent assays using a single clinical sample for diagnosis of acute DENV infection. Clin Vaccine Immunol 2008, 15:1513-1518.

10. Guzman MG, Jaenisch T, Gaczkowski R, Ty Hang VT, Sekaran SD, Kroeger A, Vazquez S, Ruiz D, Martinez E, Mercado JC, Balmaseda A, Harris E, Dimano E, Leano PS, Yoksan S, Villegas E, Benduzu H, Villalobos I, Farrar J, Simmons CP: Multi-country evaluation of the sensitivity and specificity of two commercially-available NS1 ELISA assays for dengue diagnosis. PLOS Negl Trop Dis 2010, 4:e811.

11. Blacksell SD, Jarman RG, Gibbons RV, Tanganuchitcharnchai A, Mammen MP Jr, Nisalak A, Kalayanarooj S, Bailey MS, Premaratna R, de Silva HJ, Day NP, Lalloo DG: Comparison of seven commercial antigen and antibody enzyme-linked immunosorbent assays for detection of acute dengue infection. Clin Vaccine Immunol 2012, 19:804-810.

12. Blacksell SD, Jarman RG, Bailey MS, Tanganuchitcharnchai A, Jenjaroen K, Gibbons RV, Paris DH, Premaratna R, de Silva HJ, Lalloo DG, Day NP: Evaluation of six commercial point-of-care tests for diagnosis of acute dengue infections: the need for combining NS1 antigen and $\operatorname{lgM} / \mathrm{lgG}$ antibody detection to achieve acceptable levels of accuracy. Clin Vaccine Immunol 2011, 18:2095-2011.

13. Hang VT, Nguyet NM, Trung DT, Tricou V, Yoksan S, Dung NM, Van Ngoc T, Hien TT, Farrar J, Wills B, Simmons CP: Diagnostic accuracy of NS1 ELISA and lateral flow rapid tests for dengue sensitivity, specificity and relationship to viraemia and antibody responses. PLoS Negl Trop Dis 2009, 3:e360.

14. Ramirez AH, Moros Z, Comach G, Zambrano J, Bravo L, Pinto B, Vielma S, Cardier J, Liprandi F: Evaluation of dengue NS1 antigen detection tests with acute sera from patients infected with dengue virus in Venezuela. Diagn Microbiol Infect Dis 2009, 65:247-253.

15. Duyen HT, Ngoc TV, Ha Do T, Hang VT, Kieu NT, Young PR, Farrar JJ, Simmons CP, Wolbers M, Wills BA: Kinetics of plasma viremia and soluble nonstructural protein 1 concentrations in dengue: differential effects according to serotype and immune status. J Infect Dis 2011, 203:1292-1300.

16. Duong V, Ly S, Lorn Try P, Tuiskunen A, Ong S, Chroeung N, Lundkvist A, Leparc-Goffart I, Deubel V, Vong S, Buchy P: Clinical and virological factors influencing the performance of a NS1 antigen-capture assay and potential use as a marker of dengue disease severity. PLoS Negl Trop Dis 2011, 5:e1244.

17. Koraka P, Burghoorn-Maas CP, Falconar A, Setiati TE, Djamiatun K, Groen J, Osterhaus AD: Detection of immune-complex-dissociated nonstructural-1 antigen in patients with acute dengue virus infections. J Clin Microbiol 2003, 41:4154-4159.

18. Green MA, Sviland L, Malcolm AJ, Pearson AD: Improved method for immunoperoxidase detection of membrane antigens in frozen sections. J Clin Pathol 1989, 42:875-880.

19. Falconar AK, de Plata E, Romero-Vivas CM: Altered enzyme-linked immunosorbent assay immunoglobulin $\mathrm{M}$ (IgM)/lgG optical density ratios can correctly classify all primary or secondary dengue virus infections 1 day after the onset of symptoms, when all of the viruses can be isolated. Clin Vaccine Immunol 2006, 13:1044-1051.

20. Falconar AKI, Romero-Vivas CME: Simple prognostic criteria can definitively identify patients who develop severe versus non-severe dengue disease, or have other febrile illnesses. J Clin Med Res 2012, 4:33-44.

21. Falconar AKI: The dengue virus non-structural-1 protein (NS1) generates antibodies to common epitopes on human blood clotting, integrin/ adhesion proteins and binds to human endothelial cells: potential implications in haemorrhagic fever pathogenesis. Arch Virol 1997, 142:897-916.

22. Falconar AKl: Antibody responses are generated to immunodominant ELK KLE-type motifs on the dengue virus non-structural-1 glycoprotein during live dengue virus infections in mice and humans: implications for diagnosis, pathogenesis, and vaccine design. Clin Vaccine Immunol 2007, 14:493-504.

23. Libraty DH, Young PR, Pickering D, Endy TP, Kalayanarooj S, Green S, Vaughn DW, Nisalak A, Ennis FA, Rothman AL: High circulating levels of the dengue virus nonstructural protein NS1 early in dengue illness correlate with the development of dengue hemorrhagic fever. J Infect Dis 2002, 186:1165-1168.

24. McBride WJ: Evaluation of dengue NS1 test kits for the diagnosis of dengue fever. Diagn Microbiol Infect Dis 2009, 64:31-36.

25. Lapphra K, Sangcharaswichai A, Chokephaibulkit K, Tiengrim S, Piriyakarnsakul W, Chakorn T, Yoksan S, Wattanamongkolsil L, Thamlikitkul V: Evaluation of an NS1 antigen detection for diagnosis of acute dengue infection in patients with acute febrile illness. Diagn Microbiol Infect Dis 2008, 60:387-391.

26. Tricou V, Minh NN, Farrar J, Tran HT, Simmons CP: Kinetics of viremia and NS1 antigenemia are shaped by immune status and virus serotype in adults with dengue. PLoS Negl Trop Dis 2011, 5:e1309.

27. Chanama S, Anantapreecha S, A-nuegoonpipat A, Sa-gnasang A, Kurane I, Sawanpanyalert $P$ : Analysis of specific IgM responses in secondary dengue virus infections: levels and positive rates in comparison with primary infections. J Clin Virol 2004, 31:185-189.

28. Carrington CV, Foster JE, Pybus OG, Bennett SN, Holmes EC: Invasion and maintenance of dengue virus type 2 and type 4 in the Americas. J Virol 2005, 79:14680-14687.

29. Allicock OM, Lemey P, Tatem AJ, Pybus OG, Bennett SN, Mueller BA, Suchard MA, Foster JE, Rambaut A, Carrington CV: Phylogeography and population dynamics of dengue viruses in the Americas. Mol Biol Evol 2012, 29:1533-1543. 
30. Carrillo-Valenzo E, Danis-Lozano R, Velasco-Hernández JX, Sánchez-Burgos G, Alpuche C, López I, Rosales C, Baronti C, de Lamballerie X, Holmes EC, Ramos-Castañeda J: Evolution of dengue virus in Mexico is characterized by frequent lineage replacement. Arch Virol 2010, 155:1401-1412.

31. OhAinle M, Balmaseda A, Macalalad AR, Tellez Y, Zody MC, Saborío S, Nuñez A, Lennon NJ, Birren BW, Gordon A, Henn MR, Harris E: Dynamics of dengue disease severity determined by the interplay between viral genetics and serotype-specific immunity. Sci Trans/ Med 2011, 3:114ra128.

32. Tang Y, Quintana M, Zhang C, Li T, Sauls D, Putnak R, Alvarado SC, Castro DJ, Matute ML, Lynch JA: Letter to the editor: molecular genotyping of Dengue Virus Types 2 and 4 from the Guatemalan and Honduran Epidemics of 2007 using the envelope glycoprotein gene. Virus Genes 2011, 42:200-203.

33. de Souza RP, Rocco IM, Maeda AY, Spenassatto C, Bisordi I, Suzuki A, Silveira VR, Silva SJ, Azevedo RM, Tolentino FM, Assis JC, Bassi MG, Dambrós BP, Tumioto GL, Gregianini TS, Souza LT, Timenetsky Mdo C, Santos CL: Dengue virus type 4 phylogenetics in Brazil 2011: looking beyond the veil. PLoS Negl Trop Dis 2011, 5:e1439.

34. Thomas L, Verlaeten O, Cabié A, Kaidomar S, Moravie V, Martial J, Najioullah F, Plumelle Y, Fonteau C, Dussart P, Césaire R: Influence of the dengue serotype, previous dengue infection, and plasma viral load on clinical presentation and outcome during a dengue- 2 and dengue- 4 coepidemic. Am J Trop Med Hyg 2008, 78:990-998.

35. Sabchareon A, Sirivichayakul C, Limkittikul K, Chanthavanich P, Suvannadabba S, Jiwariyavej V, Dulyachai W, Pengsaa K, Margolis HS, Letson GW: Dengue infection in children in Ratchaburi, Thailand: a cohort study. I. Epidemiology of symptomatic acute dengue infection in children, 2006-2009. PLoS Negl Trop Dis 2012, 6:e1732.

36. Lee KS, Lo S, Tan SS, Chua R, Tan LK, Xu H, Ng LC: Dengue virus surveillance in Singapore reveals high viral diversity through multiple introductions and in situ evolution. Infect Genet Evol 2012, 12:77-85.

37. Wu W, Bai Z, Zhou H, Tu Z, Fang M, Tang B, Liu J, Liu L, Liu J, Chen W: Molecular epidemiology of dengue viruses in southern China from 1978 to 2006. Virol J 2011, 8:322.

38. Falconar AKI: Identification of an epitope on the dengue virus membrane (M) protein defined by cross-reactive monoclonal antibodies: design of an improved epitope sequence based on common determinants present in both envelope ( $E$ and M) proteins. Arch Virol 1999, 144:2313-233.

39. Wüthrich $\mathrm{M}$, Finkel-Jiminez BE, Klein BS: Interleukin 12 as an adjuvant to WI-1 adhesin immunization augments delayed-type hypersensitivity, shifts the subclass distribution of immunoglobulin $\mathrm{G}$ antibodies, and enhances protective immunity to Blastomyces dermatitidis infection. Infect Immun 2000, 68:7172-7174.

doi:10.1186/1743-422X-10-126

Cite this article as: Falconar and Romero-Vivas: A simple, inexpensive, robust and sensitive dot-blot assay for equal detection of the nonstructural-1 glycoprotein of all dengue virus serotypes. Virology Journal 2013 10:126.

\section{Submit your next manuscript to BioMed Central and take full advantage of:}

- Convenient online submission

- Thorough peer review

- No space constraints or color figure charges

- Immediate publication on acceptance

- Inclusion in PubMed, CAS, Scopus and Google Scholar

- Research which is freely available for redistribution 